\title{
Nonlinear dynamics of a novel fractional-order Francis hydro-turbine governing system with time delay
}

\author{
Feifei Wang ${ }^{1}$, Diyi Chen ${ }^{1,2}$, Beibei Xu ${ }^{1}$, Hao Zhang $^{1}$ \\ ${ }^{1}$ Institute of Water Resources and Hydropower Research, Northwest A\&F University, Shaanxi \\ Yangling 712100, P. R. China \\ ${ }^{2}$ Department of Mathematics and Statistics, Faculty of Science and Engineering Curtin University, \\ Perth Western Australia 6845, Australia
}

\section{Corresponding author: Di-Yi Chen}

Mailing Address: Institute of Water Resources and Hydropower Research, Northwest A\&F University, Shaanxi Yangling 712100, China

Telephones: 086-181-6198-0277

E-mail: diyichen@nwsuaf.edu.cn

Abstract: This paper focuses on the stability of a hydropower station. First, we established a novel nonlinear mathematical model of a Francis hydro-turbine governing system considering both fractional-order derivative and time delay. The fractional-order $\alpha$, which is introduced into the penstock system, in the range from 0.82 to 1.00 is on the left side of the model in a incommensurate manner in increment of 0.03 to provide an adjustable degree of system memory. The time delay $\tau$, which exists between the signal and response in the hydraulic servo system, in the range from $0 s$ to $0.26 s$ is inserted on the right side of the model in increment of $0.04 s$. Utilizing the principle of statistical physics, we respectively explored the effects of the fractional-order $\alpha$ and the time delay $\tau$ on the stable region of the system. Furthermore, we exhaustively investigated the nonlinear dynamic behaviors of the system with different governor parameters by using bifurcation diagrams, time waveforms and power spectrums, finding that only under the condition of reasonable collocation of governor parameters the system can maintain stable operation. Finally, all of the 
above numerical experiments supply new methods for studying the stability of a hydropower station. Key words: hydro-turbine governing system; nonlinear mathematical model; time delay; fractional order; bifurcation 


\section{Introduction}

Hydroelectric power's low cost, near-zero pollution emissions, and ability to quickly respond to peak loads make it a valuable renewable energy source. In the past decade, hydropower has a rapid rate of development in China [1]. The total installed generation capacity of hydropower stations in China has now surpassed $200 \mathrm{GW}$, and ranks first in the world [2, 3]. The safe and stable operation of a hydropower station not only makes a positive contribution to social development, but also provides a powerful driving force for the sustainable development of the national economy [4]. Therefore, ensuring the stable operation of the hydropower station is an important work. As is well known, a hydro-turbine governing system (HTGS), as one of the most important parts of a hydropower station, plays a vital role in the stable operation of a hydropower station. Thus, the study of the stability of the HTGS becomes necessary and urgent. Fortunately, there are many contributions to the modeling of the HTGS and corresponding stability analyses based on the integer order calculus [5-9]. For example, Lai [7] studied the hydraulic stability of a Francis hydro-turbine by using numerical simulation. Nagode and Skrjanc [8] proposed a dynamic model of a Francis hydro-turbine with a surge tank, and realized a fuzzy power control approach to determine unknown parameters. $\mathrm{Xu}$ and $\mathrm{Li}$ [9] using the analytical method built a finite element rotor model and investigated the influence of unbalanced magnetic pull on the radial vibration of large hydro-turbine generators. However, considering that the HTGS is essentially a complex nonlinear, time-variant and non-minimum phase system $[10,11]$, previous researches with integer order calculus have some limitations on reflecting the real vibration mechanism of the HTGS. Moreover, to simplify the modeling of the HTGS, previous literatures ignored some factors which have a bad effect on the stable operation of the HTGS, such as the flow inertia of the penstock system, the time delay of the hydraulic servo system, and random disturbance of power load, etc [12, 13]. Therefore, it is 
necessary to establish a new mathematical model for the HTGS.

Mandelbrot [14] pointed out that there are many fractional dimension phenomena in nature and technology, namely, many physical systems exhibit fractional-order dynamical behaviors because of their special constituent materials and chemical properties. Fractional order calculus, as the extension of integer order calculus, provides a novel approach to modeling the dynamics of the physical system. Unlike integer order calculus, the 'fractional' approach can include all of the past information of the system [15-18]. That is to say, fractional order calculus can reflect the evolution process of the physical system involving memory effect. Therefore, to examine those special phenomena arising in complex and heterogeneous materials, fractional order calculus has been widely used into various branches of science and engineering, such as viscoelastic mechanics [19], dielectric polarization [20, 21], signal processing [22, 23], control engineering [24] and so on. With respect to the HTGS, fractional order calculus with powerful memory can make its dynamic characteristics much closer to reality, thus we attempt to introduce fractional order calculus into the modeling of the HTGS.

From the point of view of an engineer, the prior work about the HTGS focused on the nonlinear, integer-order mathematical modeling without the time delay, cannot be able to explain all of the observed vibration phenomena. The reason is that the objective law of the movement of nonlinear system depends not only on its current state but also on its previous state $[25,26]$. That is to say, the influence of the previous state of the nonlinear system on its current state has a time delay. The time delay, as an objective existence, can enrich the nonlinear dynamics and supply a precise description for the real life phenomena [27-29]. Due to these features, the time delay has been introduced into control system [30], financial system [31], population dynamics [32], chemical kinetics [33], epidemiology [34], etc. Although the time delay is small in many engineering practices, it has a 
great negative effect on the stability and controllability of the nonlinear system. Consequently, as regards the HTGS, we attempt to introduce the time delay into its modeling to investigate its stability.

Motivated by the above discussions, considering that the dead zone of the main control valve causes the servomotor to remain stationary, and the displacement response of the servomotor piston has a lag in time, we innovatively introduced the time delay into the hydraulic servo system. Also, Caputo fractional order calculus was creatively introduced into the penstock system in view of its constituent material that makes it exhibit obvious viscoelastic properties. Thus, a novel fractional-order nonlinear mathematical model of a Francis hydro-turbine governing system with time delay was presented. From the above model, the effects of the fractional-order $\alpha$ and the time delay $\tau$ on the stable region of the HTGS were investigated, respectively. Utilizing bifurcation diagrams, time waveforms and power spectrums, we also explored the dynamic characteristics of the HTGS in detail with different governor parameters.

The rest of this paper is organized as follows. In Section 2, we briefly introduce some definitions. Section 3 establishes a novel fractional-order nonlinear mathematical model of a Francis hydro-turbine governing system with time delay. Furthermore, the stability of the above system is investigated by using numerical experiments in Section 4. Section 5 closes this paper.

\section{Nomenclature}

\begin{tabular}{|l|l|}
\hline Symbol & Quantity \\
\hline$m_{t}$ & $\begin{array}{l}\text { the relative deviation of the hydro-turbine torque, p.u. } \\
\text { the relative deviation of the hydro-turbine discharge, p.u. } \\
q\end{array}$ \\
$\begin{array}{ll}\text { the relative deviation of the guide vane opening, p.u. } \\
\text { the relative deviation of the rotate speed, p.u. }\end{array}$ \\
\hline
\end{tabular}




\begin{tabular}{|c|c|}
\hline$h$ & the relative deviation of the hydro-turbine head, p.u. \\
\hline$Q(s)$ & the Laplace transform of $q$, p.u. \\
\hline$H(s)$ & the Laplace transform of $h$, p.u. \\
\hline$G_{h}(s)$ & the transfer function of penstock system, p.u. \\
\hline$e_{y}, e_{x}, e_{h}$ & the partial derivatives of the hydro-turbine torque with respect to the guide vane \\
\hline$e_{q y}, e_{q x}, e_{q h}$ & $\begin{array}{l}\text { opening, the rotate speed and the hydro-turbine head, p.u. } \\
\text { the partial derivatives of the hydro-turbine discharge with respect to the guide }\end{array}$ \\
\hline & vane opening, the rotate speed and the hydro-turbine head, p.u. \\
\hline$h_{w}$ & the characteristic constant of the penstock, p.u. \\
\hline$T_{r}$ & the reflection time of the penstock, $\mathrm{s}$ \\
\hline$T_{w}$ & the water inertia time constant of the penstock system, s \\
\hline$T_{y}$ & the response time constant of the servomotor, $\mathrm{s}$ \\
\hline$T_{a}$ & the unit inertia time constant, $\mathrm{s}$ \\
\hline$T_{b}$ & the load inertia time constant, $\mathrm{s}$ \\
\hline$e_{n}$ & the self-regulation coefficient of the hydroelectric generating set, p.u. \\
\hline$e_{g}$ & the self-regulation coefficient of the generator load, p.u. \\
\hline$m_{g 0}$ & the load disturbance of the power grid, $\mathrm{N} \cdot \mathrm{m}$ \\
\hline$u$ & the output signal of the governor system, p.u. \\
\hline$r$ & the reference input of the rotate speed, p.u. \\
\hline$k_{p}$ & the proportional gain of a PID controller, p.u. \\
\hline$k_{i}$ & the integral gain of a PID controller, $\mathrm{s}^{-1}$ \\
\hline$k_{d}$ & the differential gain of a PID controller, $\mathrm{s}$ \\
\hline$\tau$ & the time delay, s \\
\hline$\alpha$ & the fractional order \\
\hline
\end{tabular}




\section{Preliminaries}

In general, there are three different definitions of fractional derivatives which are often used, namely, Riemann-Liouville fractional derivative, Grünwald-Letnikov fractional derivative, and Caputo fractional derivative. The former two definitions are mostly used in the field of pure mathematics, while the last one is frequently applied to Science and Engineering [35]. Accordingly, here we only introduce Caputo fractional derivative which will be used in deriving the nonlinear dynamical model of the HTGS. Also, some basic definitions that are used in this paper are given below.

Definition 2.1 The (left sided) Caputo fractional derivative of order $\alpha>0$ for a function $f \in C^{n}([a, b], R)$ is defined as [36]

$$
{ }_{a}^{C} D_{t}^{\alpha} f(t)=\frac{1}{\Gamma(n-\alpha)} \int_{a}^{t} \frac{f^{(n)}(u)}{(t-u)^{1+\alpha-n}} d u
$$

where $n$ is the first integer not less than $\alpha$, that is, $n-1<\alpha<n ; C^{n}([a, b], R)$ is the set of all $n$ order continuous differentiable functions on $[a, b] ; \Gamma(\cdot)$ is the well-known Euler's Gamma-function.

Definition 2.2 The discrete fractional-order nonlinear system with time delay can be defined as [37]

$$
\left\{\begin{array}{l}
{ }_{0}^{C} D_{t}^{\alpha} y(t)=f(t, y(t), y(t-\tau)), t \in[0, T], 0<\alpha \leq 1 \\
y(t)=g(t), \quad t \in[-\tau, 0]
\end{array},\right.
$$

where ${ }_{0}^{C} D_{t}^{\alpha}$ is the left sided Caputo fractional derivative; $y(t)$ is the state vector of the system, and $y(t)=\left[y_{1}(t), y_{2}(t), \cdots, y_{n}(t)\right]^{T} \in R^{n} ; \tau$ is the discrete time delay, and $\tau=\left[\tau_{1}, \tau_{2}, \cdots, \tau_{n}\right]^{T}$; $g(t) \in C\left([-\tau, 0], \mathrm{R}^{n}\right) ; \quad f(t, y(t), y(t-\tau))$ is Lipschitz continuous in $[-\tau,+\infty) \times G(G \subset R)$, and $f(t, y(t), y(t-\tau))=\left[f_{1}(t, y(t), y(t-\tau)), \cdots, f_{n}(t, y(t), y(t-\tau))\right]^{T} \in R^{n}$

\section{Fractional-order modeling of the HTGS with time delay}

The structure diagram of the HTGS [39] is shown in Fig. 1. From Fig. 1, we see that the HTGS, 
as a closed loop system, is composed of the hydro-turbine control system and the controlled system. The hydro-turbine control system consists of the measuring module, the setting module, the amplification module, the main servomotor and the feedback module. The controlled system includes the penstock system, the hydroelectric generating set and the electrical system. Also, we can easily know the operational principle of the hydroelectric generation as follows. Water first flows through the penstock system, and then enters into the scroll casing. Subsequently, the hydro-turbine begins to rotate by using the hydroenergy, i.e. the hydro-turbine head $H$ and the hydro-turbine discharge $Q$. Then, the synchronous generator is driven to generate electricity to meet the electricity requirements of the electrical system. However, considering the load disturbance and the frequency disturbance existing in the electrical system, the system parameters of the hydroelectric generating set, namely the frequency $f$, the power $P_{g}$, the hydro-turbine head $H$ and the hydro-turbine discharge $Q$, always produce random fluctuations that the whole system cannot keep in a stable state. In this case, by measuring the deviation values and the change trends of the above parameters, the hydro-turbine control system takes corresponding control strategy to maintain the governing system in its stable state.

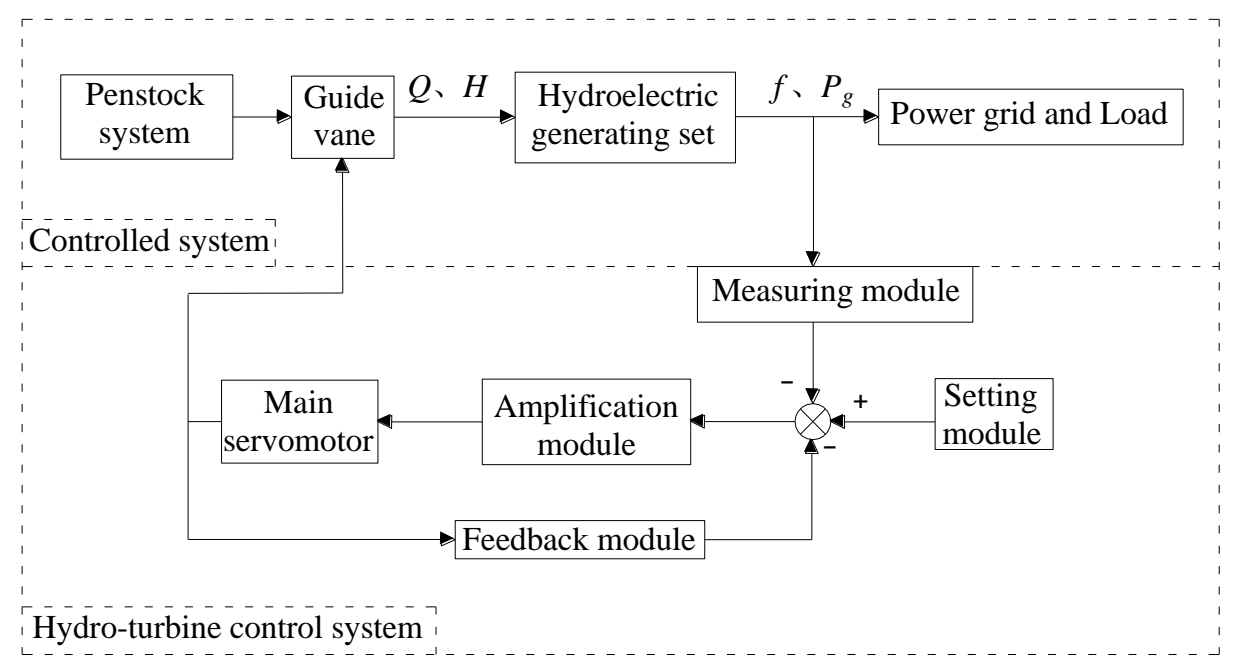

Fig. 1. The structure diagram of a hydro-turbine governing system.

In the following contents, we will select a Francis hydro-turbine governing system as the study 
object. Also, the whole system will be divided into five parts, i.e. the Francis hydro-turbine, the penstock system, the generator system, the hydraulic servo system and the governor system. From Ref. [40] and Ref. [41], we can obtain models of the Francis hydro-turbine, the generator system and the governor system. Considering the engineering practices, however, we respectively modify models of the penstock system and the hydraulic servo system based on Ref. [43] and Ref. [47].

\subsection{Nonlinear mathematical model of the Francis hydro-turbine}

From Ref. [40] and Ref. [41], we get the dynamic model of the Francis hydro-turbine as

$$
\left\{\begin{array}{l}
m_{t}=e_{y} y+e_{x} x+e_{h} h \\
q=e_{q y} y+e_{q x} x+e_{q h} h
\end{array},\right.
$$

where $m_{t}, q, h, x$ and $y$ denote the relative deviations of the hydro-turbine torque, the hydro-turbine discharge, the hydro-turbine head, the rotate speed and the guide vane opening, respectively; $e_{y}, e_{x}$ and $e_{h}$ are respectively the partial derivatives of the hydro-turbine torque with respect to the guide vane opening, the rotate speed and the hydro-turbine head, and $e_{y}=e_{y m}(h+1), e_{x}=e_{x m} \sqrt{h+1}$ and $e_{h}=e_{h m} ; e_{q y}, e_{q x}$ and $e_{q h}$ respectively denote the partial derivatives of the hydro-turbine discharge with respect to the guide vane opening, the rotate speed and the hydro-turbine head, and $e_{q y}=e_{q y m} \sqrt{h+1}, e_{q x}=e_{q x m}$ and $e_{q h}=e_{q h m} \frac{1}{x+1} ; e_{y m}, e_{x m}, e_{h m}$, $e_{q y m}, e_{q x m}$ and $e_{q h m}$ can be acquired by using dynamic characteristics of the hydro-turbine torque.

\subsection{The mathematical model of the generator system}

Till now, there are mainly four different generator models that are usually used to explore dynamic characteristics of the generator system, that is, the first-order generator model, the second-order generator model, the third-order generator model and the seventh-order generator model. For the sake of simplicity only the first-order generator model is introduced here, and its mathematical equation is presented as [43] 


$$
x^{\prime}=\frac{1}{T_{a b}}\left(m_{t}-m_{g 0}-e_{n} x\right)
$$

where $T_{a b}=T_{a}+T_{b}, T_{a}$ is the unit inertia time constant, $T_{b}$ is the load inertia time constant; $e_{n}$ is the self-regulation coefficient of the hydroelectric generating set, $e_{g}$ is the self-regulation coefficient of the generator load, and $e_{n}=e_{g}-e_{x} ; m_{g 0}$ is the load disturbance of the power grid.

\subsection{The mathematical model of the governor system}

At present, the parallel PID controller is widely used in the governor system, and its output signal is described as [41]

$$
u=k_{p}(r-x)+k_{i} x_{4}-k_{d} x^{\prime}
$$

where $r$ is the reference input of the rotate speed, and here we set $r=0.0 ; x_{4}$ is the state variable, and $x_{4}=\int_{0}^{t}(r-x) d t ; k_{p}, k_{i}$ and $k_{d}$ respectively denote the proportional gain, the integral gain and the differential gain of the PID controller.

\subsection{The mathematical model of the hydraulic servo system with time delay}

The servomotor, which acts as the actuator, is used to amplify the control signal and supply power for operating the guide vane. From Ref. [41] and Ref. [43], we get the mathematical model of the hydraulic servo system as

$$
y^{\prime}=\frac{1}{T_{y}}(u-y),
$$

where $T_{y}$ is the response time constant of the servomotor; $u$ is the output signal of the governor system.

However, considering the fact that the dead zone of the main control valve causes the servomotor to remain stationary and the displacement response of the servomotor piston has a lag in time, the hydraulic servo system requires some time to make responses when the displacement signal is detected by the measuring module. From the mathematical point of view, the traditional 
model of the hydraulic servo system i.e. Eq. (6) without including time delay, cannot reflect the real-time characteristic of the hydraulic servo system.

To reflect such phenomena, the time delay, which can enrich the nonlinear dynamics and provide a precise description for the real life phenomena, can be included into the hydraulic servo system, i.e. by introducing a discrete time delay into the nonlinear dynamic function of the servomotor. In view of that there are many examples which successfully introduced the discrete time delay into their models [44-46], we based on Definition 2.2 similarly get the nonlinear dynamic equation of the servomotor with the time delay as

$$
y=y(t)=\left\{\begin{array}{l}
y(t-\tau), \quad t \in[\tau,+\infty] \\
y_{0}, \quad t \in\left[\begin{array}{ll}
0, & \tau]
\end{array},\right.
\end{array}\right.
$$

where $\tau$ is the time delay, and $\tau>0$.

Therefore, we get the mathematical model of the hydraulic servo system with time delay as

$$
y^{\prime}=\left\{\begin{array}{l}
\frac{1}{T_{y}}(u-y(t-\tau)), \quad t \in[\tau,+\infty] \\
\frac{1}{T_{y}}\left(u-y_{0}\right), \quad t \in[0, \tau]
\end{array},\right.
$$

\subsection{Fractional-order mathematical model of the penstock system}

As is well known, the penstock and water both have elastic properties which seriously affect the stability of the HTGS. So we introduce the elastic water hammer model of the penstock system in this paper. From Ref. [47], the transfer function of the penstock system is expressed as

$$
G_{h}(s)=\frac{H(s)}{Q(s)}=-h_{w} \frac{T_{r} s+\frac{1}{24} T_{r}^{3} s^{3}}{1+\frac{1}{8} T_{r}^{2} s^{2}},
$$

where $h_{w}$ is the characteristic constant of the penstock; $T_{r}$ is the reflection time of the penstock, which reflects the intensity of the elastic water hammer to a certain degree.

From Eq. (9), the state-space equations of the penstock system is obtained as 


$$
\left\{\begin{array}{l}
x_{1}^{\prime}=x_{2}-\frac{3}{T_{w}} h \\
x_{2}^{\prime}=x_{3} \\
x_{3}^{\prime}=-\frac{24}{T_{r}^{2}} x_{2}+\frac{48}{T_{r}^{2} T_{w}} h \\
q=x_{1}
\end{array}\right.
$$

where $x_{1}, x_{2}$ and $x_{3}$ are state variables; $T_{w}$ is the water inertia time constant of the penstock system, and $T_{w}=T_{r} h_{w}$.

Meanwhile, combining the second formula of Eq. (3) and the fourth formula of Eq. (10), we get the nonlinear dynamic equation of the hydro-turbine head as

$$
h^{\prime}=\frac{1}{e_{q h}}\left\{\frac{e_{q x}\left(e_{g}-2 e_{x}\right)}{T_{a b}} x+\left(\frac{e_{q y} T_{a b}-e_{q x} e_{y} T_{y}}{T_{y} T_{a b}}\right) y-\left(\frac{e_{q x} e_{h}}{T_{a b}}+\frac{3}{T_{w}}\right) h+x_{2}-\frac{e_{q y}}{T_{y}} u+\frac{e_{q x}}{T_{a b}} m_{g 0}\right\} .
$$

Actually, Design Specification for Steel Penstocks of Hydroelectric Stations (SL281-2003) rules that the constituent material of the penstock system is killed steel which has low-temperature impact toughness. Meanwhile, Design Specification for Steel Penstocks of Hydroelectric Stations (SL281-2003) stipulates that the steel penstocks can be regarded as the isotropic and homogenized elastomer in calculations. In addition, Ref. [47] indicated that water flowing in the penstock system possesses viscoelasticity. Thus, it is not hard to find that the penstock system has obvious viscoelastic properties which have a great effect on its dynamic behaviors.

Nevertheless, the prior model of the penstock system i.e. Eq. (11), has certain limitations on studying the dynamic characteristics of the HTGS, without considering the viscoelasticity existing in the penstock system. In view of the advantages of fractional order calculus in modeling viscoelastic substance and the excellent performance of fractional order calculus in describing time evolution of the physical process, we introduce Caputo fractional order calculus into the modeling of the penstock system. Based on the definition of Caputo fractional order calculus, we obtain the 
fractional-order dynamic model of the penstock system as

$$
\left\{\begin{array}{l}
x_{1}^{\prime}=x_{2}-\frac{3}{T_{w}} h \\
x_{2}{ }^{\prime}=x_{3} \\
x_{3}^{\prime}=-\frac{24}{T_{r}^{2}} x_{2}+\frac{48}{T_{r}^{2} T_{w}} h \\
D^{\alpha} h=\frac{1}{e_{q h}}\left\{\frac{e_{q x}\left(e_{g}-2 e_{x}\right)}{T_{a b}} x+\left(\frac{e_{q y} T_{a b}-e_{q x} e_{y} T_{y}}{T_{y} T_{a b}}\right) y-\left(\frac{e_{q x} e_{h}}{T_{a b}}+\frac{3}{T_{w}}\right) h+x_{2}-\frac{e_{q y}}{T_{y}} u+\frac{e_{q x}}{T_{a b}} m_{g 0}\right\}
\end{array} .\right.
$$

According to the above discussions, combining every part of the HTGS into an organic unity, we get the fractional-order nonlinear mathematical model of the HTGS with time delay as

$$
\left\{\begin{array}{l}
x_{1}^{\prime}=x_{2}-\frac{3}{T_{w}} h \\
x_{2}^{\prime}=x_{3} \\
x_{3}^{\prime}=-\frac{24}{T_{r}^{2}} x_{2}+\frac{48}{T_{r}^{2} T_{w}} h \\
x_{4}^{\prime}=r-x \\
x^{\prime}=\frac{1}{T_{a b}}\left[\left(2 e_{x m} \sqrt{h+1}-e_{g}\right) x+e_{y m}(h+1) y_{0}+e_{h m} h-m_{g 0}\right] \\
y^{\prime}=\frac{1}{T_{y}}\left[k_{p}(r-x)+k_{i} x_{4}-k_{d} x^{\prime}-y_{0}\right] \\
D^{\alpha} h=\frac{(x+1)}{e_{q h m}}\left\{\frac{e_{q x m}\left(e_{g}-2 e_{x m} \sqrt{h+1}\right)}{T_{a b}} x+\frac{e_{q y m} \sqrt{h+1} T_{a b}-e_{q x m} e_{y m}(h+1) T_{y}}{T_{y} T_{a b}} y_{0}\right. \\
\left.-\left(\frac{e_{q x m} e_{h m}}{T_{a b}}+\frac{3}{T_{w}}\right) h+x_{2}-\frac{e_{q y m} \sqrt{h+1}}{T_{y}}\left[k_{p}(r-x)+k_{i} x_{4}-k_{d} x^{\prime}\right]+\frac{e_{q x m}}{T_{a b}} m_{g 0}\right\}
\end{array}, \quad, 0 \leq t \leq \tau\right.
$$

and

$$
\left\{\begin{array}{l}
x_{1}^{\prime}=x_{2}-\frac{3}{T_{w}} h \\
x_{2}^{\prime}=x_{3} \\
x_{3}^{\prime}=-\frac{24}{T_{r}^{2}} x_{2}+\frac{48}{T_{r}^{2} T_{w}} h \\
x_{4}^{\prime}=r-x \\
x^{\prime}=\frac{1}{T_{a b}}\left[\left(2 e_{x m} \sqrt{h+1}-e_{g}\right) x+e_{y m}(h+1) y(t-\tau)+e_{h m} h-m_{g 0}\right] \\
y^{\prime}=\frac{1}{T_{y}}\left[k_{p}(r-x)+k_{i} x_{4}-k_{d} x^{\prime}-y(t-\tau)\right] \\
D^{\alpha} h=\frac{(x+1)}{e_{q h m}}\left\{\frac{e_{q x m}\left(e_{g}-2 e_{x m} \sqrt{h+1}\right)}{T_{a b}} x+\frac{e_{q y m} \sqrt{h+1} T_{a b}-e_{q x m} e_{y m}(h+1) T_{y}}{T_{y} T_{a b}} y(t-\tau)\right. \\
\left.-\left(\frac{e_{q x m} e_{h m}}{T_{a b}}+\frac{3}{T_{w}}\right) h+x_{2}-\frac{e_{q y m} \sqrt{h+1}}{T_{y}}\left[k_{p}(r-x)+k_{i} x_{4}-k_{d} x^{\prime}\right]+\frac{e_{q x m}}{T_{a b}} m_{g 0}\right\}
\end{array}, t>\tau .\right.
$$




\section{Numerical experiments}

Here, the modified Admas-Bashforth-Moulton algorithm for solving fractional-order differential equations with the time delay (see Appendix A), is used in the subsequent numerical experiments. The fixed step is 0.02 , and the initial value of the HTGS is considered as $\left[x_{1}, x_{2}, x_{3}, x_{4}, x, y, h\right]^{T}=[0.001,0.001,0.001,0.001,0.001,0.001,0.001]^{T} \quad . \quad$ Moreover, $\quad$ other $\quad$ system parameters are all calculated based on the parameters of the hydroelectric generating set of the Zhouning hydropower plant. Considering that Ref. [41] and Ref. [42] have calculated the values of these system parameters, we directly give these system parameters listed in Tab. 1.

Tab. 1. System parameters of the hydro-turbine governing system.

\begin{tabular}{cccccc}
\hline Parameters & Values & Units & Parameters & Values & Units \\
\hline$e_{x m}$ & -1.0673 & p.u. & $T_{w}$ & 2.8 & $\mathrm{~s}$ \\
$e_{y m}$ & 0.7713 & p.u. & $T_{r}$ & 1.7 & $\mathrm{~s}$ \\
$e_{h m}$ & 1.7179 & p.u. & $T_{y}$ & 0.6 & $\mathrm{~s}$ \\
$e_{q x m}$ & -0.2901 & p.u. & $m_{g 0}$ & 0.3 & p.u. \\
$e_{q y m}$ & 0.8184 & p.u. & $e_{g}$ & 0.7 & p.u. \\
$e_{q h m}$ & 0.7257 & p.u. & $k_{d}$ & 6 & $\mathrm{~s}$ \\
$T_{a b}$ & 11 & s & $k_{i}$ & 0.7 & $\mathrm{~s}^{-1}$ \\
\hline
\end{tabular}

\subsection{The influence of time delay and fractional order on the stability of the HTGS}

The bifurcation diagrams of the rotate speed about governor parameter $k_{p}$, which are used to investigate the effects of different time delays and fractional orders on the stability of the HTGS, are shown in Fig. 2. 


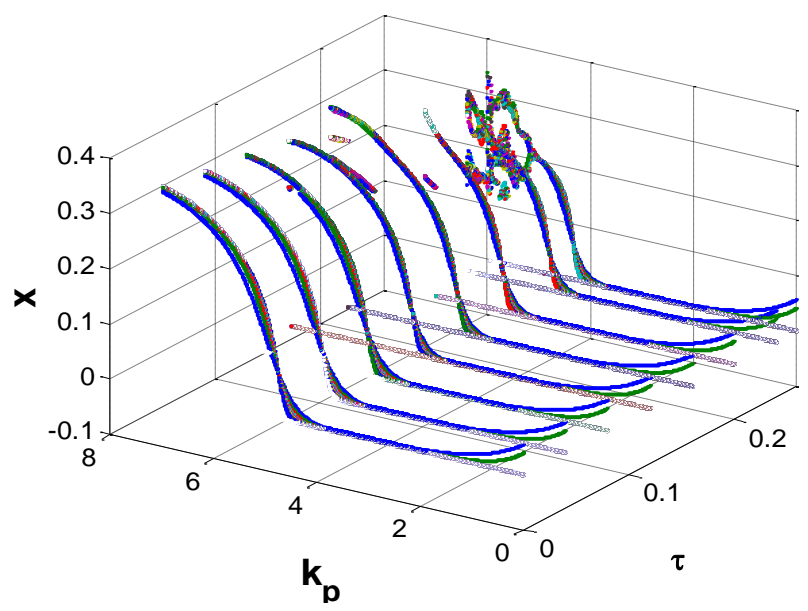

(a) $\alpha=1$

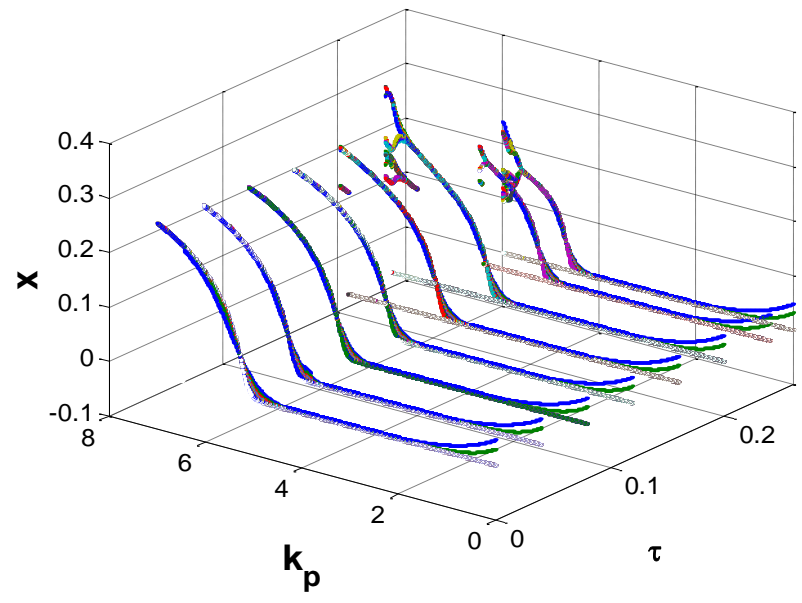

(c) $\alpha=0.94$

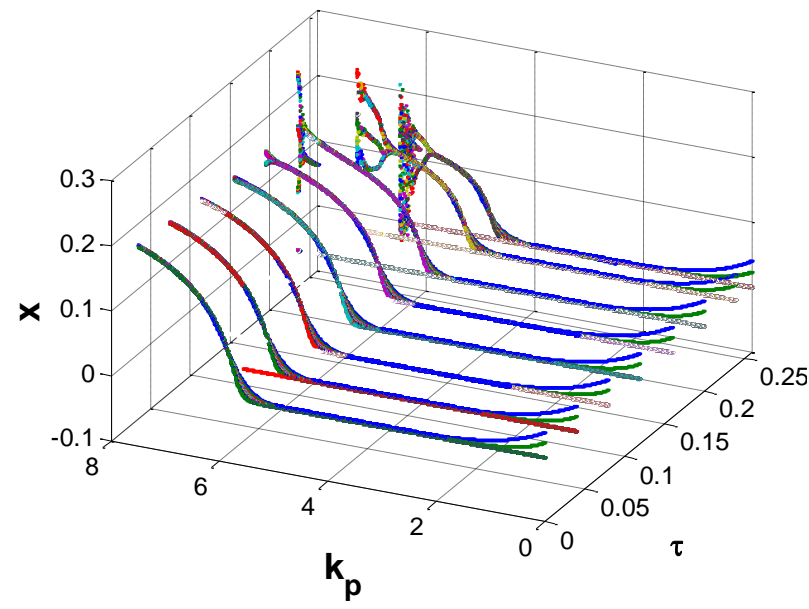

(e) $\alpha=0.88$

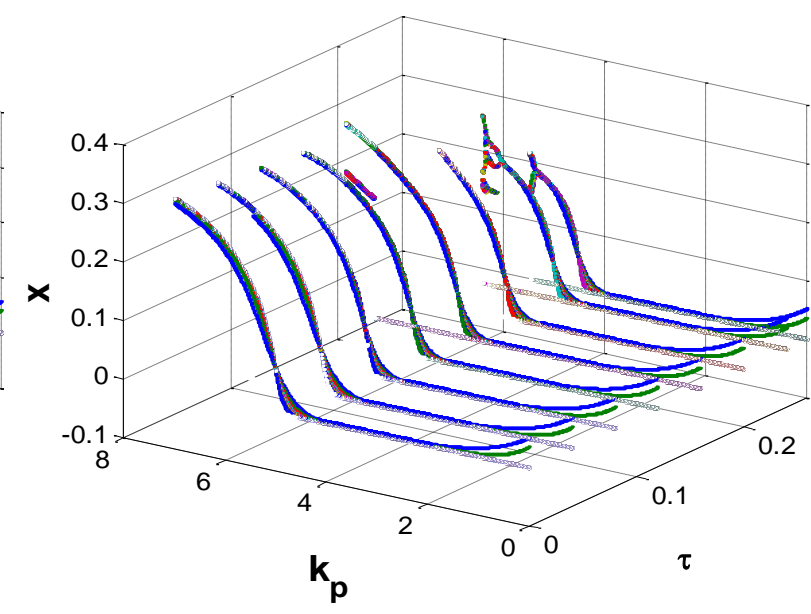

(b) $\alpha=0.97$

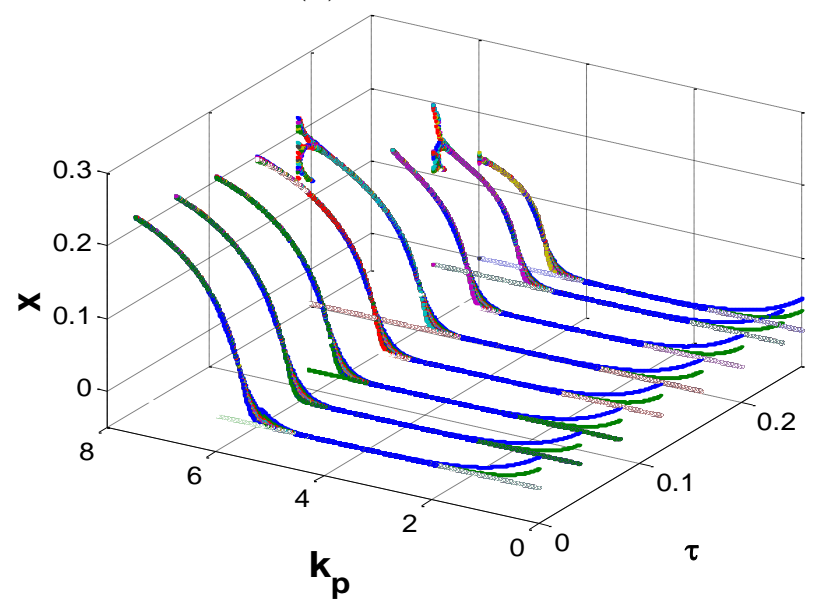

(d) $\alpha=0.91$

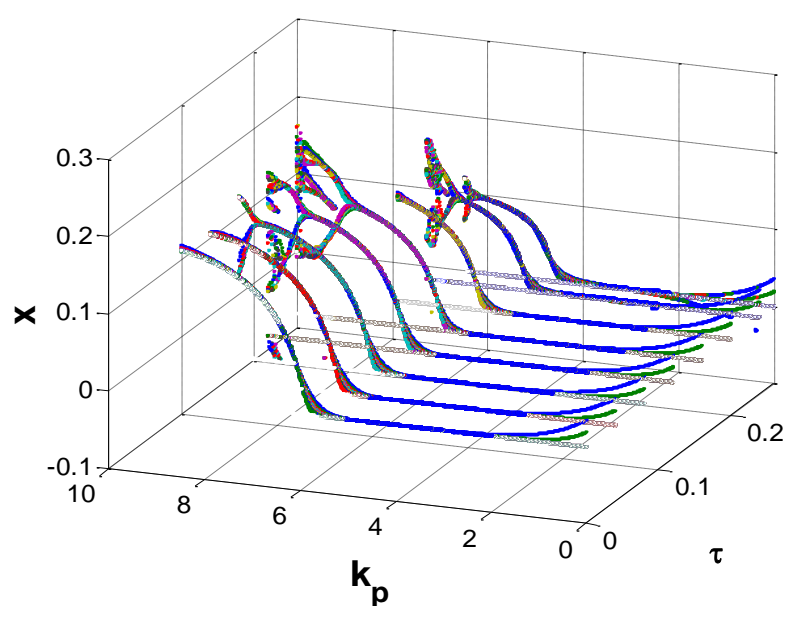

(f) $\alpha=0.85$ 


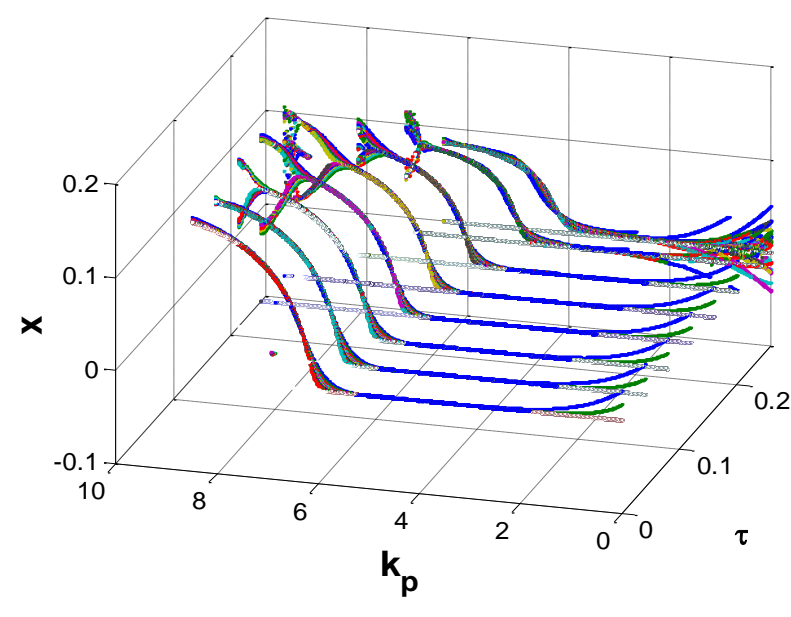

(g) $\alpha=0.82$

Fig. 2. Bifurcation diagrams of the hydro-turbine governing system about governor parameter $k_{p}$ with different fractional-order $\alpha$ and time delay $\tau$. (a) $\alpha=1 ;(b) \quad \alpha=0.97 ;(c) \quad \alpha=0.94 ;(d)$ $\alpha=0.91 ;(e) \quad \alpha=0.88 ;(f) \quad \alpha=0.85 ;(g) \quad \alpha=0.82$.

From Fig. 2, we can clearly observe that the bifurcation diagrams provide a summary of the nonlinear dynamic characteristics of the HTGS with different time delays and fractional orders. Fig. 2(a) shows, for fractional-order $\alpha=1.0$, values of bifurcation points of the system gradually decrease with the increase of the time delay $\tau$ (see Tab. 2), which means the stable region of the system is gradually decreasing. Moreover, we find that the dynamic behaviors resulting from various time delays are similar to each other. More specifically, regardless of the size of the time delay $\tau$, for small values of governor parameter $k_{p}$ (for example, $k_{p}<2$ ), the relative deviation of the rotate speed $x$ always fluctuates around zero as $k_{p}$ increases. It indicates the frequency of the hydroelectric generating set cannot keep at its rated value, and the service voltage of electric power is unstable. Thus, its power quality may not meet the requirements of the electrical system, and the above small range of governor parameter $k_{p}$ should not be adopted to regulate the hydroelectric generating set. However, for large values of governor parameter $k_{p}$ (for example, $2<k_{p}<3.5$ ), the relative deviation of the rotate speed $x$ is constant as $k_{p}$ increases, and its value is zero. It means that the frequency of the hydroelectric generating set maintains at its rated value, and the 
service voltage of electric power is stable, indicating its power quality can satisfy the requirements of the electrical system. Subsequently, as governor parameter $k_{p}$ increases across its bifurcation point, the rotate speed keeps in the state of large amplitude oscillation, whose amplitude increases with the increasing governor parameter $k_{p}$. Obviously, the HTGS is in an unstable state, and the electrical system also cannot keep in safe and steady operation state. Interestingly, for $\tau=0.24, k_{p}>5.64$ and $\tau=0.26, k_{p}>5.172$, the rotate speed of the system presents multiple periodic oscillation, showing the HTGS may be out of control.

In Fig. 2(b)- $(g)$, for fractional-order $0.82 \leq \alpha \leq 0.97$ in increment of 0.03 , the dynamic characteristics of the HTGS as the time delay $\tau$ increases are almost similar to those of the integer order ( $\alpha=1$ ). Differently, for fractional-order $\alpha=0.85$ and $\alpha=0.82$, the system emerges multiple periodic oscillation phenomenon while the time delay $\tau$ is very small (for example, $\tau=0.08)$. It means that the system will appear regular vibrations with small fractional-order $\alpha$, even if the time delay $\tau$ is very small which can be ignored. Moreover, we have also investigated the stability of the HTGS for fractional-order $\alpha<0.82$ (for example $\alpha=0.79$ ) in our laboratory, finding that its dynamic characteristics with increasing time delay $\tau$ are almost the same with those of $0.82 \leq \alpha \leq 1$. But, unlike $0.82 \leq \alpha \leq 1$, the stable region of the HTGS for fractional-order $\alpha=0.79$ disappears when the time delay $\tau=0.26$. These numerical experiment results again indicate that the system will emerge sustained vibration and even lose stability under the common action of smaller fractional-order $\alpha$ and bigger time delay $\tau$.

On the whole, as shown in Fig. 2, the stable region of the system decreases with the increase of time delay $\tau$, no matter what values of the fractional-order $\alpha$. When the value of the time delay $\tau$ is confirmed, however, the stable region of the system increases with decreasing fractional-order $\alpha$ (see Tab. 2). It is to be observed that the change law of the stable region of the system for 
$\tau=0.24$ and $\tau=0.26$ is different from those of $0 \leq \tau \leq 0.20$.

Using the principle of statistical physics, we have listed the stable region of the HTGS in Tab. 2 to clearly illustrate its change law with different fractional-order $\alpha$ and time delay $\tau$. Correspondingly, these bifurcation points of the HTGS have been plotted in Fig. 3 .

Tab. 2. The stable region of the HTGS with different fractional-order $\alpha$ and time delay $\tau$.

\begin{tabular}{|c|c|c|c|c|c|}
\hline $\begin{array}{l}\text { Time } \\
\text { delay }\end{array}$ & $\begin{array}{c}\text { Fractional } \\
\text { order }\end{array}$ & $\begin{array}{c}\text { Stable region of } \\
k_{p}\end{array}$ & $\begin{array}{l}\text { Time } \\
\text { delay }\end{array}$ & $\begin{array}{c}\text { Fractional } \\
\text { order }\end{array}$ & $\begin{array}{c}\text { Stable region of } \\
k_{p}\end{array}$ \\
\hline \multirow{7}{*}{$\tau=0 s$} & $\alpha=1.00$ & $(0,4.757)$ & \multirow{7}{*}{$\tau=0.16 s$} & $\alpha=1.00$ & $(0,4.558)$ \\
\hline & $\alpha=0.97$ & $(0,5.032)$ & & $\alpha=0.97$ & $(0,4.805)$ \\
\hline & $\alpha=0.94$ & $(0,5.305)$ & & $\alpha=0.94$ & $(0,5.040)$ \\
\hline & $\alpha=0.91$ & $(0,5.580)$ & & $\alpha=0.91$ & $(0,5.267)$ \\
\hline & $\alpha=0.88$ & $(0,5.853)$ & & $\alpha=0.88$ & $(0,5.468)$ \\
\hline & $\alpha=0.85$ & $(0,6.099)$ & & $\alpha=0.85$ & $(0,5.628)$ \\
\hline & $\alpha=0.82$ & $(0,6.341)$ & & $\alpha=0.82$ & $(0,5.695)$ \\
\hline \multirow{7}{*}{$\tau=0.04 s$} & $\alpha=1.00$ & $(0,4.716)$ & \multirow{7}{*}{$\tau=0.20 s$} & $\alpha=1.00$ & $(0,4.487)$ \\
\hline & $\alpha=0.97$ & $(0,4.982)$ & & $\alpha=0.97$ & $(0,4.720)$ \\
\hline & $\alpha=0.94$ & $(0,5.254)$ & & $\alpha=0.94$ & $(0,4.939)$ \\
\hline & $\alpha=0.91$ & $(0,5.524)$ & & $\alpha=0.91$ & $(0,5.135)$ \\
\hline & $\alpha=0.88$ & $(0,5.788)$ & & $\alpha=0.88$ & $(0,5.277)$ \\
\hline & $\alpha=0.85$ & $(0,6.036)$ & & $\alpha=0.85$ & $(0,5.366)$ \\
\hline & $\alpha=0.82$ & $(0,6.247)$ & & $\alpha=0.82$ & $(0,5.396)$ \\
\hline \multirow{7}{*}{$\tau=0.08 s$} & $\alpha=1.00$ & $(0,4.671)$ & \multirow{7}{*}{$\tau=0.24 s$} & $\alpha=1.00$ & $(0,4.397)$ \\
\hline & $\alpha=0.97$ & $(0,4.931)$ & & $\alpha=0.97$ & $(0,4.608)$ \\
\hline & $\alpha=0.94$ & $(0,5.195)$ & & $\alpha=0.94$ & $(0,4.795)$ \\
\hline & $\alpha=0.91$ & $(0,5.453)$ & & $\alpha=0.91$ & $(0,4.938)$ \\
\hline & $\alpha=0.88$ & $(0,5.704)$ & & $\alpha=0.88$ & $(0,5.020)$ \\
\hline & $\alpha=0.85$ & $(0,5.918)$ & & $\alpha=0.85$ & $(0,5.010)$ \\
\hline & $\alpha=0.82$ & $(0,6.097)$ & & $\alpha=0.82$ & $(0,4.825)$ \\
\hline
\end{tabular}




\begin{tabular}{|c|c|c|c|c|c|}
\hline & $\alpha=1.00$ & $(0,4.620)$ & & $\alpha=1.00$ & $(0,4.342)$ \\
\hline & $\alpha=0.97$ & $(0,4.871)$ & & $\alpha=0.97$ & $(0,4.538)$ \\
\hline & $\alpha=0.94$ & $(0,5.126)$ & & $\alpha=0.94$ & $(0,4.702)$ \\
\hline$\tau=0.12 s$ & $\alpha=0.91$ & $(0,5.367)$ & $\tau=0.26 s$ & $\alpha=0.91$ & $(0,4.805)$ \\
\hline & $\alpha=0.88$ & $(0,5.590)$ & & $\alpha=0.88$ & $(0,4.827)$ \\
\hline & $\alpha=0.85$ & $(0,5.801)$ & & $\alpha=0.85$ & $(0,4.688)$ \\
\hline & $\alpha=0.82$ & $(0,5.942)$ & & $\alpha=0.82$ & $(0,4.232)$ \\
\hline
\end{tabular}

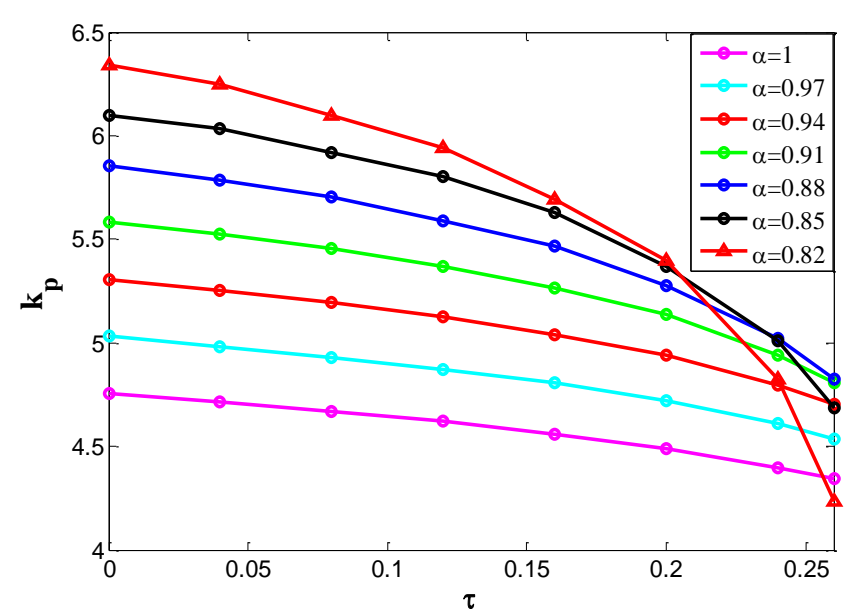

(a)

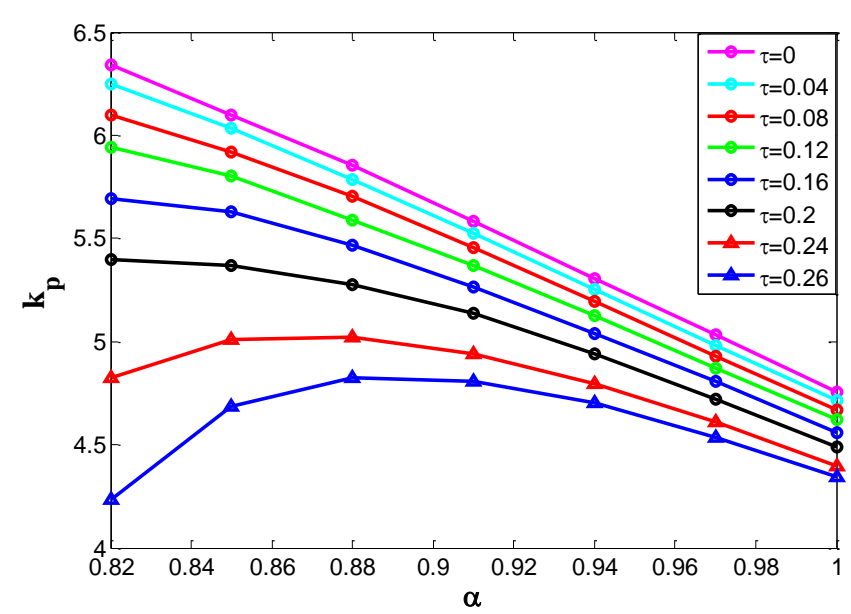

(b)

Fig. 3. Change law of bifurcation points of the hydro-turbine governing system with different fractional-order $\alpha$ and time delay $\tau$. (a) For different fractional-order $\alpha$, bifurcation point of the hydro-turbine governing system $k_{p}$ versus time delay $\tau$. (b) For different time delay $\tau$, bifurcation point of the hydro-turbine governing system $k_{p}$ versus fractional-order $\alpha$.

Fig. 3(a) shows, for different fractional-order $\alpha$, the bifurcation point $k_{p}$ as a decreasing function of the time delay $\tau$. More specifically, for $0.91 \leq \alpha \leq 1$, the bifurcation points decrease in the almost linear form along with the increase of the time delay $\tau$. As regards $0.82 \leq \alpha \leq 0.88$, however, the bifurcation points and time delays constitute a monotonic decreasing nonlinear curve, whose curvature increases with the decrease of fractional-order $\alpha$. As shown in Fig. 3(b), we observe that, with regard to $0 \leq \tau \leq 0.2$, the bifurcation points $k_{p}$ and fractional orders $\alpha$ form a monotonic decreasing approximate straight line. Similarly, when $\tau=0.24$ and $\tau=0.26$, for large 
values of $\alpha$ (for example $0.88 \leq \alpha \leq 1$ ), the bifurcation points $k_{p}$ also increase with the decreasing fractional-orders $\alpha$. However, for $\tau=0.24$ and $\tau=0.26$, bifurcation points $k_{p}$ quickly reduce to smaller values as fractional-order $\alpha$ decreases from 0.88 to 0.82 . More importantly, we find that the HTGS is stable when governor parameter $k_{p}$ reads values under these curves shown in Fig. 3. In other words, under the common action of the fractional-order $\alpha$ and the time delay $\tau$, we give the stable region of the HTGS and its change law utilizing the principle of the statistical physics.

\subsection{Dynamic behaviors of the HTGS with certain fractional-order $\alpha$ and time delay $\tau$}

In the following contents, to specifically illustrate the dynamic behaviors of the HTGS, we take the fractional-order $\alpha=0.88$ and the time delay $\tau=0.24$ as an example, and choose four representative points in Fig. 2(e), namely $k_{p}=1.0, k_{p}=2.6, k_{p}=5.02$ and $k_{p}=6.6$.

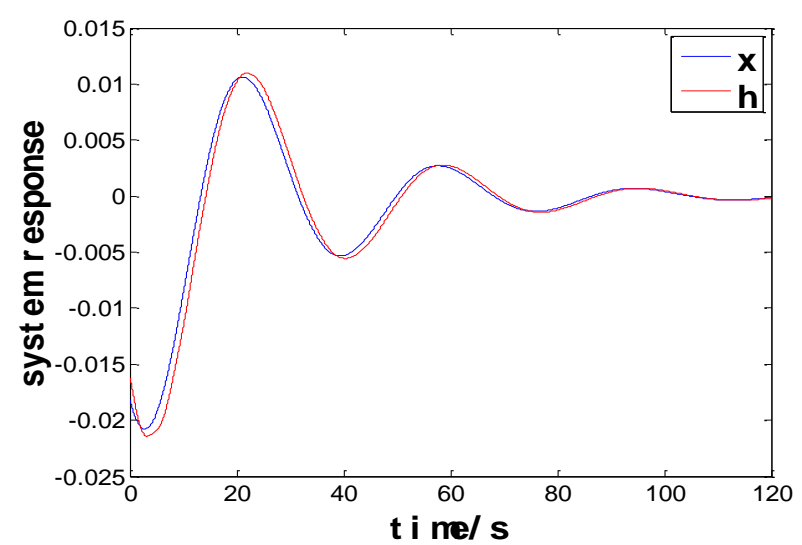

(a1) Time waveforms with $k_{p}=1.0$

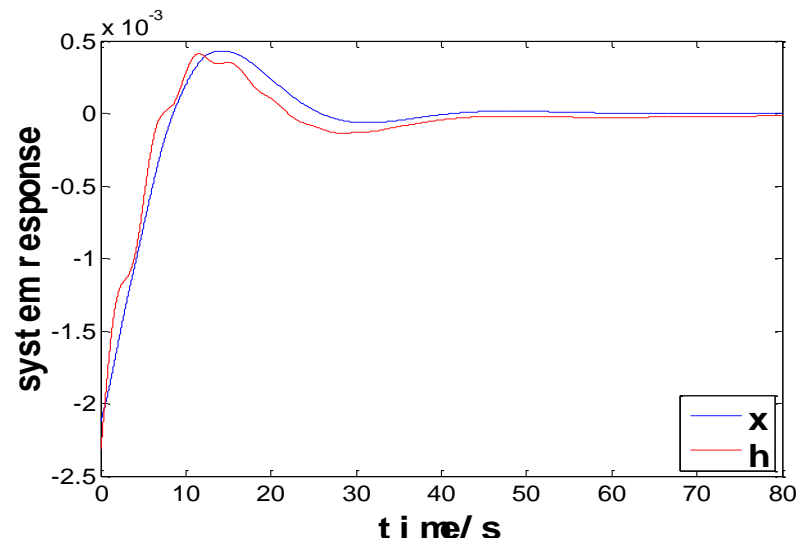

(b1) Time waveforms with $k_{p}=2.6$

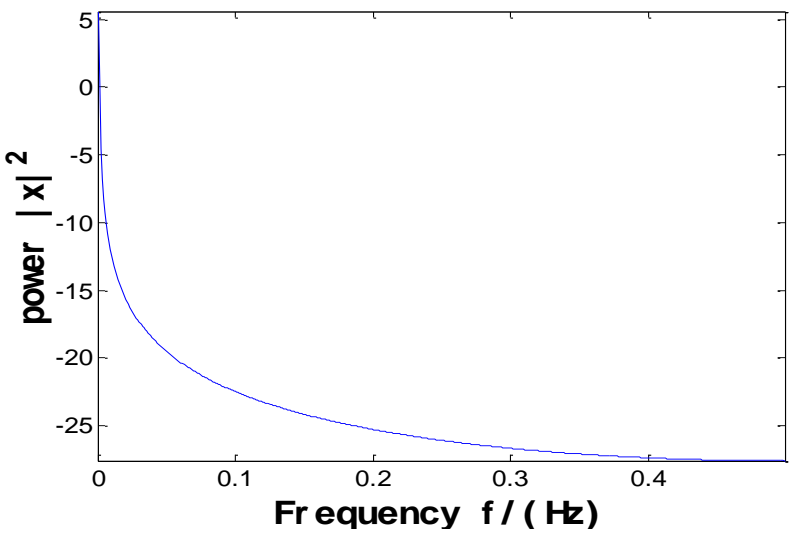

(a2) Power spectrum with $k_{p}=1.0$

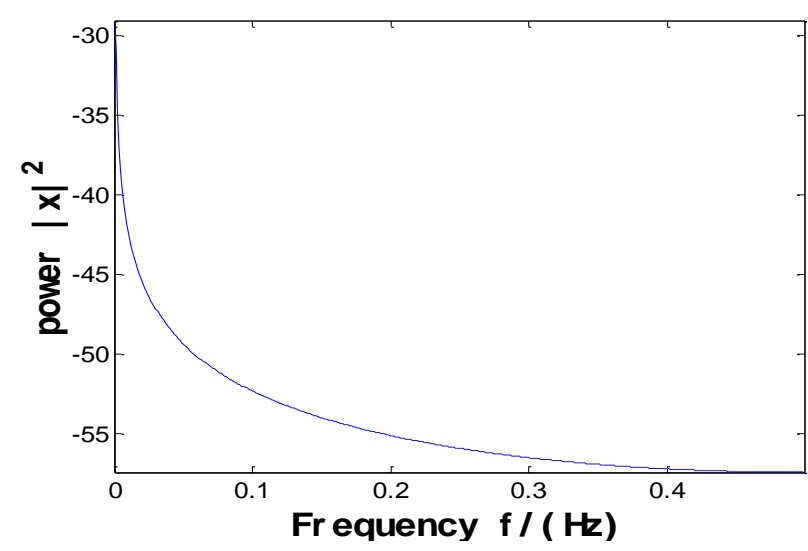

(b2) Power spectrum with $k_{p}=2.6$ 


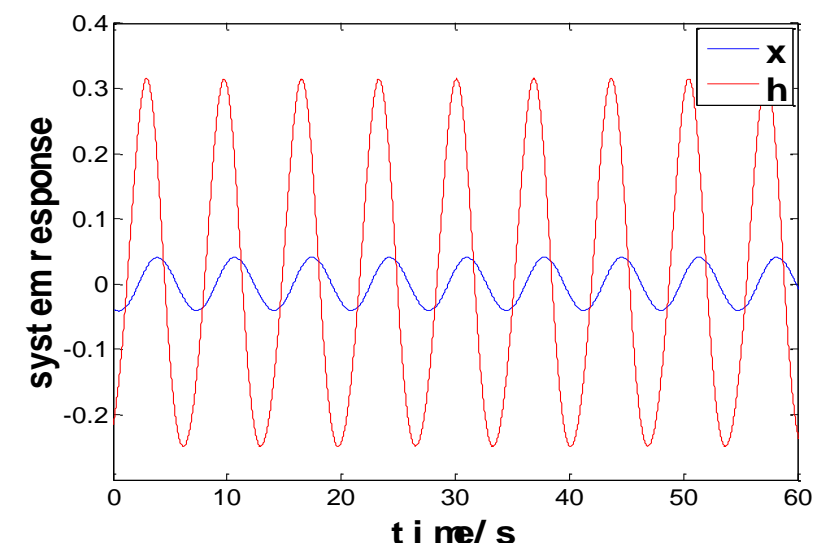

(c1) Time waveforms with $k_{p}=5.02$

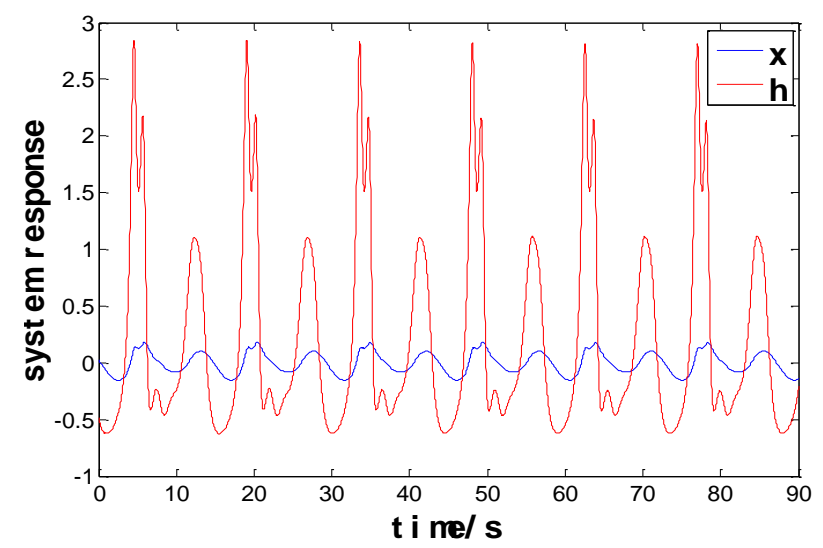

(d1) Time waveforms with $k_{p}=6.6$

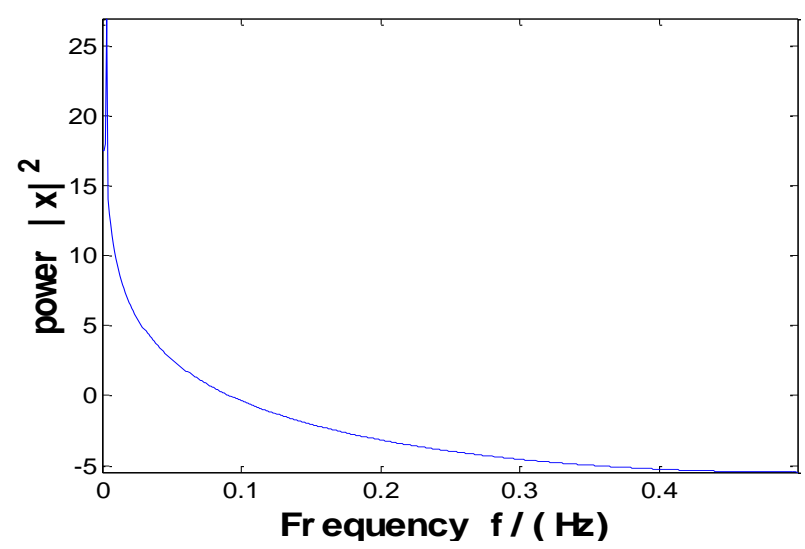

(c2) Power spectrum with $k_{p}=5.02$

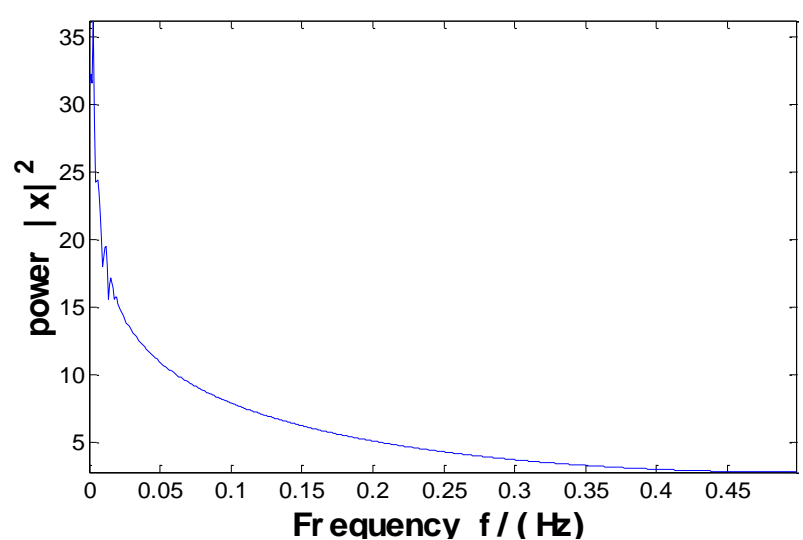

(d2) Power spectrum with $k_{p}=6.6$

Fig. 4. Time waveforms and power spectrums of the hydro-turbine governing system with different $k_{p}$ when the fractional-order $\alpha=0.88$ and the time delay $\tau=0.24$. (a1) Time waveforms with $k_{p}=1.0$. (a2) Power spectrum with $k_{p}=1.0$. (b1) Time waveforms with $k_{p}=2.6$. (b2) Power spectrum with $k_{p}=2.6 .(c 1)$ Time waveforms with $k_{p}=5.02 .(c 2)$ Power spectrum with $k_{p}=5.02 .(d 1)$ Time waveforms with $k_{p}=6.6 .(d 2)$ Power spectrum with $k_{p}=6.6$.

Fig. 4(a) shows, for $k_{p}=1.0$, the dynamic responses of the rotate speed and hydro-turbine head are similar to each other, and both slowly tend to corresponding rated values in the oscillation pattern. Note that the HTGS costs 110 seconds to enter into a steady state. Also, the maximum relative deviation of the rotate speed is 0.0108 , meaning the frequency of the hydroelectric generating set deviates from its rated value $0.54 \mathrm{~Hz}$. Considering that the rated value of the rotate speed of the hydroelectric generating set of the Zhouning hydropower plant is $500 \mathrm{r} / \mathrm{min}$ [42], we 
can obtain that the present rotate speed is $505.4 \mathrm{r} / \mathrm{min}$ which has diverged from its rated value. These numerical results indicate that the HTGS cannot quickly and safely go into the grid-connected operation state, which may be caused by the smaller value of the governor parameter $k_{p}$.

After the value of the governor parameter $k_{p}$ is increased to 2.6, the system responses are shown in Fig. 4(b). We observe that the motion amplitudes of the system are quite small, and smoothly converge towards the steady state after a smaller overshoot emerged. Meanwhile, there is a low ebb near the rated values of the system. Note that the frequency of the hydroelectric generating set deviates from its rated value $0.0215 \mathrm{~Hz}$ at most, satisfying the requirements of the power quality of the GB/T 15945-2008 (allowable deviation of the frequency of the electrical system is $\pm 0.2 \mathrm{~Hz}$ ). In addition, the system only takes 41 seconds to enter into the stable state, and the energy of the system mainly focuses on $0.001 \mathrm{~Hz}$ as shown in Fig. $4(b 2)$. Thus, for governor parameter $k_{p}=2.6$, the system can quickly and steadily enter into the grid-connected operation state.

Similarly, we continue to increase the value of the governor parameter $k_{p}$ from 2.6 to 5.02 (bifurcation point). The dynamic behaviors of the system are displayed in Fig. 4(c). We see that the rotate speed and hydro-turbine head both keep in periodic motion whose cycle is 6.78s. Accordingly, their relative deviations are \pm 0.0411 and \pm 0.3152 , respectively. Note that the rotate speed of the hydroelectric generating set fluctuates around its rated value, and its maximum value is $520.55 \mathrm{r} / \mathrm{min}$. At the same time, the frequency of the hydroelectric generating set fluctuates around its rated value, and its oscillation is $2.055 \mathrm{~Hz}$. Obviously, the HTGS keeps in an unstable state with the governor parameter $k_{p}=5.02$. The reason for these phenomena may be caused by the larger value of the governor parameter $k_{p}$.

Subsequently, as shown in Fig. 4(d), we investigate the dynamic characteristics of the system with governor parameter $k_{p}=6.6$. Note that the system responses present multiple periodic 
oscillations with large amplitudes, and the maximum relative deviations of the rotate speed and hydro-turbine head respectively reaches 0.1782 and 2.845 . It is not hard to find that the rotate speed of the hydroelectric generating set reaches $589.1 \mathrm{r} / \mathrm{min}$ which seriously diverges from $500 \mathrm{r} / \mathrm{min}$. Also, the frequency of the hydroelectric generating set deviates from its rated value $8.91 \mathrm{~Hz}$. There are $4 x$ in the power spectrum, indicating the energy of the system cannot be fixed at a certain frequency. All of the above numerical experiment results reveal that the HTGS is in an unstable state. Furthermore, we can get that too large value of the governor parameter $k_{p}$ may lead to the system out of control.

\section{Conclusions}

Since the dead zone of the main control valve causes the servomotor to remain stationary, and the displacement response of the servomotor piston has a lag in time, the modeling of the hydraulic servo system need to consider the effect of the time delay on the stability of the HTGS. At the same time, in view of the obvious viscoelastic properties of the penstock system, the Caputo fractional order calculus is introduced into the modeling of the HTGS. Based on the above two factors, we rationally developed a novel fractional-order nonlinear mathematical model of a Francis hydro-turbine governing system with time delay. By using the modified Adams-Bashforth-Moulton algorithm, we carried out the numerical experiments of the above model, and obtained three important conclusions. We first find that, no matter what the size of fractional-order $\alpha$, the stable region of the HTGS decreases gradually with the increase of the time delay $\tau$, which demonstrates the bad effects of the time delay on the stability of the HTGS. Also, the real-time characteristic of the hydraulic servo system should be improved as far as possible to ensure the stable running of the HTGS to the most degree, from the point of view of an engineer. Second, utilizing the principle of the statistical physics, the change laws of the bifurcation points of the HTGS under the common 
action of the fractional-order $\alpha$ and the time delay $\tau$ are presented. We discover that, for different time delay $\tau$, the bifurcation points of the system are increasing as fractional-order $\alpha$ decreases, indicating the stable region of the HTGS increases with the decreasing fractional-order $\alpha$. Specially, for large values of the time delay $\tau$ (for example, $\tau=0.24$ and $\tau=0.26$ ), the bifurcation points of the system do not follow its original increasing trend but decrease abruptly as fractional-order $\alpha$ decreases from 0.88 to 0.82 . Finally, we have exhaustively investigated the dynamic characteristics of the HTGS by using time waveforms and power spectrums, finding that the system can quickly and steadily tend to the rated operation state only if the PID governor parameters are reasonably coordinated. On the whole, this paper is carried out only by using numerical experiment considering the large size of hydropower plants and the constraints of experimental conditions, but the innovative introduction of the fractional order and the time delay into the modeling of the HTGS supplies a new method for the study of the stability of a hydropower station.

In view of that the time delay existing in the hydraulic servo system has a bad effect on the stability of the HTGS, we will work on a physical model of a real hydropower station system to test the real value of the time delay in our future work. Further, under different operational conditions, we will adjust the governor parameter $k_{p}$ and record the dynamic changes of the system parameters such as the guide vane opening, the hydro-turbine discharge and the rotate speed. Finally, we will compare the recording dynamic changes with the numerical experiment results to know the practical implications of these numerical experiment results.

In actual, there are multiple operational conditions of the hydroelectric generating set, such as the startup operation, the shutdown operation, the isolated grid operation, and the grid-connected operation and so on. In this paper, we studied the stability issue of the HTGS in the grid-connected 
operation. Whereas, we will study the stability problems of the HTGS in an isolated electrical system in our future work. In addition, since there are many transient phenomena such as pulsations, high-frequency pulsations and low-frequency pulsations existing in the flow of the hydro-turbine, we will attempt to modify the nonlinear mathematical model of the hydro-turbine, and then combine models of other subsystems to study the dynamic characteristics of the HTGS in the transient state.

\section{Acknowledgements}

This work was supported by the scientific research foundation of National Science Foundation (51479173, 51279167), the Fundamental Research Funds for the Central Universities (201304030577), the Scientific research funds of Northwest A\&F University （2013BSJJ095）, the scientific research foundation on water engineering of Shaanxi Province (2013slkj-12), the Science Fund for Excellent Young Scholars from Northwest A\&F University (Z109021515) and the Shaanxi nova programme (2016KJXX-55).

\section{Appendix A. Numerical method for solving fractional-order differential equations with time delay}

To solve fractional-order differential equations with the time delay, a modification of Admas-Bashforth-Moulton algorithm is presented here, which is taken from Ref. [38].

Consider the following FDDE

$$
\left\{\begin{array}{l}
{ }_{0}^{C} D_{t}^{\alpha} y(t)=f(t, y(t), y(t-\tau)), \quad t \in[0, T], 0<\alpha \leq 1 \\
y(t)=g(t), \quad t \in[-\tau, 0]
\end{array} .\right.
$$

Consider the uniform grid $\left\{t_{n}=n h: n=-k,-k+1, \cdots,-1,0,1, \cdots, N\right\}$ where $k$ and $N$ are integers satisfying $k=\tau / h$ and $N=T / h$. Let $y_{h}\left(t_{j}\right)$ be the approximation to $g\left(t_{j}\right)$ where $j=-k,-k+1, \cdots,-1,0$. Also, we can easily note that

$$
y_{h}\left(t_{j}-\tau\right)=y_{h}(j h-k h)=y_{h}\left(t_{j-k}\right), j=0,1, \cdots, N .
$$


Assume that we have already calculated approximations $y_{h}\left(t_{j}\right) \approx y\left(t_{j}\right)$ where $j=-k,-k+1, \cdots,-1,0,1, \cdots, n$, and we want to obtain $y_{h}\left(t_{n+1}\right)$ by means of the following equation

$$
y\left(t_{n+1}\right)=g(0)+\frac{1}{\Gamma(\alpha)} \int_{0}^{t_{n+1}}\left(t_{n+1}-\xi\right)^{\alpha-1} f(\xi, y(\xi), y(\xi-\tau)) \mathrm{d} \xi .
$$

Note that Eq. (17) is obtained by applying ${ }_{0} D_{t_{n+1}}^{-\alpha}$ on both sides of Eq. (15). Here we use approximations $y_{h}\left(t_{n}\right)$ for $y\left(t_{n}\right)$ in Eq. (17). Also, the integral in Eq. (17) is evaluated by using product trapezoidal quadrature formula. The corrector formula is thus

$$
\begin{aligned}
y_{h}\left(t_{n+1}\right)= & g(0)+\frac{h^{\alpha}}{\Gamma(\alpha+2)} f\left(t_{n+1}, y_{h}\left(t_{n+1}\right), y_{h}\left(t_{n+1}-\tau\right)\right) \\
& +\frac{h^{\alpha}}{\Gamma(\alpha+2)} \sum_{j=0}^{n} a_{j, n+1} f\left(t_{j}, y_{h}\left(t_{j}\right), y_{h}\left(t_{j}-\tau\right)\right) \\
= & g(0)+\frac{h^{\alpha}}{\Gamma(\alpha+2)} f\left(t_{n+1}, y_{h}\left(t_{n+1}\right), y_{h}\left(t_{n+1-k}\right)\right) \\
& +\frac{h^{\alpha}}{\Gamma(\alpha+2)} \sum_{j=0}^{n} a_{j, n+1} f\left(t_{j}, y_{h}\left(t_{j}\right), y_{h}\left(t_{j-k}\right)\right)
\end{aligned}
$$

where $a_{j, n+1}=\left\{\begin{array}{l}n^{\alpha+1}-(n-\alpha)(n+1)^{\alpha}, \text { if } j=0 \\ (n-j+2)^{\alpha+1}+(n-j)^{\alpha+1}-2(n-j+1)^{\alpha+1}, \text { if } 1 \leq j \leq n . \\ 1, \text { if } j=n+1\end{array}\right.$

Due to the unknown term $y_{h}\left(t_{n+1}\right)$ appearing on both sides of Eq. (18) and nonlinearity of $f$, Eq. (18) cannot be solved explicitly for $y_{h}\left(t_{n+1}\right)$. So we replace the term $y_{h}\left(t_{n+1}\right)$ on the right-hand side of Eq. (18) by a preliminary approximation $y_{h}^{P}\left(t_{n+1}\right)$ which is called predictor. And then Eq. (18) can be redefined as

$$
y_{h}\left(t_{n+1}\right)=g(0)+\frac{h^{\alpha}}{\Gamma(\alpha+2)} f\left(t_{n+1}, y_{h}^{P}\left(t_{n+1}\right), y_{h}\left(t_{n+1-k}\right)\right)+\frac{h^{\alpha}}{\Gamma(\alpha+2)} \sum_{j=0}^{n} a_{j, n+1} f\left(t_{j}, y_{h}\left(t_{j}\right), y_{h}\left(t_{j-k}\right)\right) .
$$

Also, product rectangle rule is used in Eq. (19) to evaluate the predictor term, i.e.

$$
\begin{aligned}
y_{h}^{P}\left(t_{n+1}\right) & =g(0)+\frac{1}{\Gamma(\alpha)} \sum_{j=0}^{n} b_{j, n+1} f\left(t_{j}, y_{h}\left(t_{j}\right), y_{h}\left(t_{j}-\tau\right)\right) \\
& =g(0)+\frac{1}{\Gamma(\alpha)} \sum_{j=0}^{n} b_{j, n+1} f\left(t_{j}, y_{h}\left(t_{j}\right), y_{h}\left(t_{j-k}\right)\right)
\end{aligned},
$$


where $b_{j, n+1}=\frac{h^{\alpha}}{\alpha}\left((n+1-j)^{\alpha}-(n-j)^{\alpha}\right)$.

Error in this method is

$$
\max _{j=-k,-k+1, \cdots,-1,0,1 \cdots, N}\left|y\left(t_{j}\right)-y_{h}\left(t_{j}\right)\right|=O\left(h^{p}\right),
$$

where $p=\min (2,1+\alpha)$. 


\section{References}

[1] Li XJ, Zhang J, Xu LY. An evaluation of ecological losses from hydropower development in Tibet. Ecol. Eng. 2015;76:178-8.

[2] Cheng CT, Liu BX, Chau KW, Li G, Liao SL. China's small hydropower and its dispatching management. Renew. Sust. Energ. Rev. 2015;42:43-13.

[3] Hennig T, Wang WL, Feng Y, Ou XK, He DM. Review of Yunnan's hydropower development. Comparing small and large hydropower projects regarding their environmental implications and socio-economic consequences. Renew. Sust. Energ. Rev. 2013;27:585-11.

[4] Huang HL, Yan Z. Present situation and future prospect of hydropower in China. Renew. Sust. Energ. Rev. 2009;13:1652-5.

[5] Zhang $\mathrm{H}$, Chen $\mathrm{DY}, \mathrm{Xu} \mathrm{BB}$, Wang FF. Nonlinear modeling and dynamic analysis of hydro-turbine governing system in the process of load rejection transient. Energy Conv. Manag. 2015;90:128-10.

[6] Hannett LN, Feltes JW, Fardanesh B, Crean W. Modeling and control tuning of a hydro station with units sharing a common penstock section. IEEE Trans. Power Syst. 1999;14:1407-6.

[7] Lai XD. Analysis and estimation of hydraulic stability of Francis hydro turbine. J. Hydrodyn. 2004;16:194-7.

[8] Nagode K, Skrjanc I. Modelling and internal fuzzy model power control of a Francis water turbine. Energies 2014;7:874-16.

[9] Xu Y, Li ZH. Computational model for investigating the influence of unbalanced magnetic pull on the radial vibration of large hydro-turbine generators. J. Vib. Acoust.-Trans. ASME 2012;134:051013.

[10] Chen DY, Ding C, Do YH, Ma XY, Zhao H, Wang YC. Nonlinear dynamic analysis for a 
Francis hydro-turbine governing system and its control. J. Frankl. Inst.-Eng. Appl. Math. 2014;351:4596-23.

[11] Date A, Date A, Akbarzadeh A. Investigating the potential for using a simple water reaction turbine for power production from low head hydro resources. Energy Conv. Manag. 2013;66:257-14.

[12] Kishor N, Singh SP, Raghuvanshi AS. Dynamic simulations of hydro turbine and its state estimation based LQ control. Energy Conv. Manag. 2006;47:18-2.

[13] Xu BB, Wang FF, Chen DY, Zhang H. Hamiltonian modeling of multi-hydro-turbine governing systems with sharing common penstock and dynamic analyses under shock load. Energy Conv. Manag. 2016;108:478-10.

[14] Mandelbrot BB. The Fractal Geometry of Nature. 1th ed. New York: W. H. Freeman \& Co Ltd, 1974.

[15] Carpinteri A, Cornetti P. A fractional calculus approach to the description of stress and strain localization in fractal media. Chaos Solitons Fractals 2002;13:85-10.

[16] Ahmad WM, Harb AM. On nonlinear control design for autonomous chaotic systems of integer and fractional orders. Chaos Solitons Fractals 2003;18:693-8.

[17] Zhang RF, Chen DY, Do YH, Ma XY. Synchronization and anti-synchronization of fractional dynamical networks. J. Vib. Control 2015;21:3383-20.

[18] Baleanu D, Magin, RL, Bhalekar S, Daftardar-Gejji V. Chaos in the fractional order nonlinear Bloch equation with delay. Commun. Nonlinear Sci. Numer. Simul. 2015;25:41-9.

[19] Tripathi D, Beg OA. Mathematica numerical simulation of peristaltic biophysical transport of a fractional viscoelastic fluid through an inclined cylindrical tube. Comput. Methods Biomech. Biomed. Eng. 2015;18:1648-10. 
[20] Ducharne B, Zhang B, Guyomar D, Sebald G. Fractional derivative operators for modeling piezoceramic polarization behaviors under dynamic mechanical stress excitation. Sens. Actuator A-Phys. 2013;189:74-6.

[21] Guyomar D, Ducharne B, Sebald G, Audiger D. Fractional Derivative Operators for Modeling the Dynamic Polarization Behavior as a Function of Frequency and Electric Field Amplitude. IEEE Trans. Ultrason. Ferroelectr. Freq. Control 2009;56:437-7.

[22] Chen DY, Zhang RF, Liu XZ, Ma XY. Fractional order Lyapunov stability theorem and its applications in synchronization of complex dynamical networks. Commun. Nonlinear Sci. Numer. Simul. 2014;19:4105-17.

[23] Mendez V, Iomin A. Comb-like models for transport along spiny dendrites. Chaos Solitons Fractals 2013;53:46-6.

[24] Agrawal SK, Srivastava M, Das S. Synchronization of fractional order chaotic systems using active control method. Chaos Solitons Fractals 2012;45:737-16.

[25] Richard JP. Time-delay systems: an overview of some recent advances and open problems. Automatica 2003;39:1667-28.

[26] Arik S. Global robust stability analysis of neural networks with discrete time delays. Chaos Solitons Fractals 2005;26:1407-8.

[27] Reese MG. Application of a time-delay neural network to promoter annotation in the Drosophila melanogaster genome. Comput. Chem. 2001;26:51-6.

[28] Gao HJ, Chen TW, Lam J. A new delay system approach to network-based control. Automatica 2008;44:39-14.

[29] Ren JG, Yang XF, Yang LX, Xu YH, Yang FZ. A delayed computer virus propagation model and its dynamics. Chaos Solitons Fractals 2012;45:74-6. 
[30] Luo C, Wang XY. Modified function projective lag synchronization in fractional-order chaotic (hyperchaotic) systems. J. Vib. Control 2014;20:1498-14.

[31] Taleizadeh AA, Nematollahi M. An inventory control problem for deteriorating items with back-ordering and financial considerations. Appl. Math. Model. 2014;38:93-17.

[32] Breedveld MC, Fitze PS. A matter of time: delayed mate encounter postpones mating window initiation and reduces the strength of female choosiness. Behav. Ecol. Sociobiol. 2015;69:533-9.

[33] Werler M, Cancino LR, Schiessl R, Maas U, Schulz C, Fikri M. Ignition delay times of diethyl ether measured in a high-pressure shock tube and a rapid compression machine. Proc. Combust. Inst. 2015;35:259-8.

[34] Balasubramaniam P, Tamilalagan P, Prakash M. Bifurcation analysis of HIV infection model with antibody and cytotoxic T-lymphocyte immune responses and Beddington-DeAngelis functional response. Math. Meth. Appl. Sci. 2015;38:1330-12.

[35] Diethelm K. An investigation of some nonclassical methods for the numerical approximation of Caputo-type fractional derivatives. Numer. Algorithms 2008;47:361-30.

[36] Liu YJ. Existence of solutions for impulsive differential models on half lines involving Caputo fractional derivatives. Commun. Nonlinear Sci. Numer. Simul. 2013;18:2604-22.

[37] Zhang XY. Some results of linear fractional order time-delay system. Appl. Math. Comput. 2008;197:407-5.

[38] Bhalekar S, Daftardar-Gejji V, Baleanu D, Magin R. Fractional Bloch equation with delay. Comput. Math. Appl. 2011;61:1355-11.

[39] Wei SP. Simulation of Hydraulic turbine regulating system. 1th ed. Chinese: Huazhong University of Science and Technology Press, Wuhan; 2011.

[40] Guo WC, Yang JD, Wang MJ, Lai X. Nonlinear modeling and stability analysis of 
hydro-turbine governing system with sloping ceiling tailrace tunnel under load disturbance. Energy Conv. Manag. 2015;106:127-12.

[41] Chen DY, Ding C, Ma XY, Yuan P, Ba DD. Nonlinear dynamical analysis of hydro-turbine governing system with a surge tank. Appl. Math. Model. 2013;37:7611-13.

[42] Ling DJ. Study on bifurcation and chaos characteristics of the hydro-turbine governing system. Published doctoral dissertation, Chinese: Hohai University, Nanjing; 2007.

[43] Li HH, Chen DY, Zhang H, Wang FF, Ba DD. Nonlinear modeling and dynamic analysis of a hydro-turbine governing system in the process of sudden load increase transient. Mech. Syst. Signal Proc. 2016; 80: 414-428.

[44] Piotrowska MJ. An immune system-tumour interactions model with discrete time delay: Model analysis and validation. Commun. Nonlinear Sci. Numer. Simul. 2016;34:185-14.

[45] Zhang L. Multi-input partial eigenvalue assignment for high order control systems with time delay. Mech. Syst. Signal Proc. 2016;72-73:376-7.

[46] Chen HF, Gao JF, Shi T, Lu RQ. H-infinity control for networked control systems with time delay, data packet dropout and disorder. Neurocomputing. 2016;179:211-8.

[47] Xu BB, Chen DY, Zhang H, Wang FF. Modeling and stability analysis of a fractional-order Francis hydro-turbine governing system. Chaos Solitons Fractals 2015;75:50-12. 